$$
\frac{1+d}{K_{0}} a \leq f(0, y) \leq \frac{1+d}{K_{0}} b \quad \forall y \in[a, b]
$$

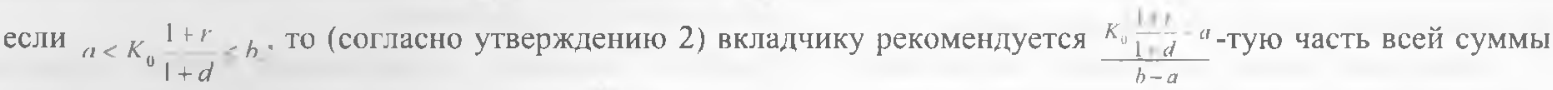
вложить в рублевой депозит, а остаток $\frac{h K_{n} \frac{1+r}{b-a}}{h-a}$ конвертировать в валюту и поместить на валютный делозит; это распределение $x^{\prime}$ дает гарантированный по рискам результат

$$
\Phi^{\prime}=\frac{\left(b-K_{0} \frac{1+r}{1+d}\right)\left(K_{0} \frac{1+r}{1+d}-a\right)(1+d)}{K_{0}(b-a)}
$$

'Таким образом, независимо от варианта реализации будушего курса валюты $y \in[a, b]$ риски (потери) $\Phi\left(x^{\prime}, y\right)$ заведомо не происходят $\Phi^{\prime}$, то есть

$$
\Phi\left(x^{r}, y\right) \leq \Phi^{r} \quad \forall y \in[a, b]
$$

В заключение заметим, что приведенная здесь математическая модель крайне упрощена - учитывает далеко не все особенности диверсификационной политики: ведь «а well-written life is almost as rare as a well-spent one».

Замечание 3. Отметим также, что рассматриваемую задачу о диверсификации единичного вклада по двум депозитам можно трактовать и как двухкритериальную. Именно, удачный выбор пропорции $x$ определяется двумя критериями. Первый из них $f_{1}(x)=x(1+r)$ соответствует стремлению вкладчика добиться возможно большего дохода от рублевого вклада, второй $f_{z}(x, y)=\frac{(1-x)}{K_{0}}(1+d) y$ характеризует доход от валютного вклада. В этой двухкритериальной задаче инвестор за счет подходящего выбора пропорции $x \in[0,1]$ стремится достичь возможно больших значений обонх критериев одновременно. При этом он должен учитывать, что будущий курс валюты $v$ ему неизвестен и может цринимать любые, заранее непредсказуемые значения из интервала $[a, b]$.

"Хороио описанная жизнь такая же редкоспь, как и хороио прожитая жизнь.»

\title{
Литература
}

1. Айзекс Р. Дифференциальные игры. - М.: Мир, 1965.

2. Ашманов С.А., Тимохов А.В. Теория оптимизации в задачах и упражнениях. М.: Наука, 1991.

3. Бережной Л.Н. Теория оптимального управления экономическими системами. Учебное пособие, Санкт-ГІетербург, 2002.

4. Васильев Н.И., Османов М.Н. Экономическая безопасность России в сфере внешнеэкономических связей. М.: Макс Пресс, 2003.

5. Воробьев Н.Н. Теория игр для экономистов-кибернетиков. - М.: Наука, 1985.

\section{ПРОФИЛЬ ДАВЛЕНИЯ СТАЦИОНАРНОЙ ДЕТОНАЦИОННОЙ ВОЛНЫ КАК ОСНОВА ТЕОРЕТИЧЕСКОЙ ОЦЕНКИ УСТОЙЧИВОСТИ ДЕТОНАЦИИ КОНДЕНСИРОВАННЫХ И ГАЗОВЫХ СИСТЕМ}

Волков В.Э., канд. физ.-мат. наук, доцент

Титигкин А.C., аспирант

Одесская вациональная академия пищевых технологий, Одесса

Произведено исследование профиля давления стационарной детонаиионной волны в рамках одноиерной модели детонации. Показано, что профиль давления стационарной детонационной волны может служить основой теоретической оченки устойчивости детонации, которая, в свою очередь, позволяет создать систеиу поддержки принятия реиений по проблемам детонаиии конденсированных и газовых систем. 
Investigation of the pressure profile of the stationary detonation wave for one-dimensional detonation model is done. It is shown that the pressure profile of the stationary detonation wave can be the basis for theoretical estimation of the detonation stability, which in its turn makes it possible to create the decision support sy'stem for the problems of the detonation of gas and condensed systems.

Ключевые слова: детонация, неустойчивость, профиль давления детонационной волны, управление, система поддержки принятия решений.

Явление детонации (от франц. detoner - взрываться) представляет собой волну горения, распространяюшуюся со сверхзвуковой скоростью. С позиций газодинамики детонация определяется как распространение в горючей смеси самоподдерживающейся ударной волны. Ударная волна скачкообразно повышает температуру до величины, превышающей минимальную температуру воспламенения смеси, и вызывает экзотермическую реакцию, энерговыделение которой поддерживает саму ударную волну $[1,2]$.

Согласно классической теории детонации предполагается, что химическая реакция локализована в узкой зоне, структура которой стационарна, причем потерями энергии в этой зоне можно пренебречь[1-3]. Такое предположение в принципе допустимо, если толщина зоны мала по сравнению с характерным размером задачи. Для гомогенных газовых смесей, в предположении что смесь предварительно хорошо перемешана и содержание реагентов находится в концентрационных пределах детонации, толщина зоны детонации составляет $\sim 10^{-4}-10^{-3}$ м $[1,2,4]$. Тогда состояния среды справа и слева от этой зоны связаны на разрыве законами сохранения массы (количества вещества), импульса (количества движения) и энергии. К этим соотношениям добавляется так называемое условие Чепмена (Chapman) -Жуге (Jouguet) [1,2,4], согласно которому скорость детонации относительно продуктов реакции равна местной скорости звука в продуктах детонации. Это условие эквивалентно требованию отсутствия возмущений фронта волны детонации со стороны продуктов реакции, чем обусловлено основное свойство самоподдерживающейся детонации - постоянство её скорости. Зная термодинамические параметры исходной горючей смеси и удельную теплоту химической реакции, а также уравнения состояния среды по обе стороны ударно-детонационного фронта, можно легко рассчитать термодинамические параметры продуктов детонации, скорость распространения детонационной волны и скорость спутного потока за ней. Такую модель детонационной волны принято называть моделью Чепмена Жуге (ЧЖ) $[1,2,4,5]$. Эта модель позволяет с высокой точностью решить многие проблемы, связанные с оценкой механического воздействия детонационных волн на окружающие предметы (детали конструкций, стенки зданий и сооружений и т.п.).

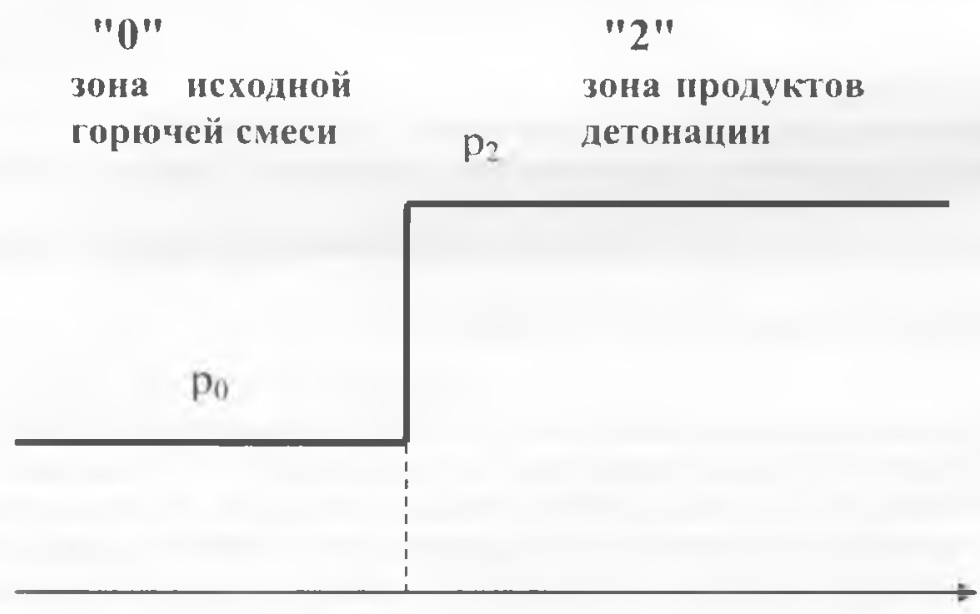

()

$\mathrm{X}$

Рис. 1 - Профиль давления в классической модели Чепмена-Жуге

Однако, при решении ряда задач теории детонации классическая модель ЧЖ, рассматривающая фронт детонации как поверхность сильного разрыва (см. Рис.1), оказывается недостаточно точной. Значительно точнее описывает процесс так называемая ЗНД-модель - модель Зельдовича - Неймана (von Neumann) Деринга (Doring), учитывающая непрерывный характер распределения термо- и газодинамических параметров за ведущим ударным фронтом (см. Рис.2). 


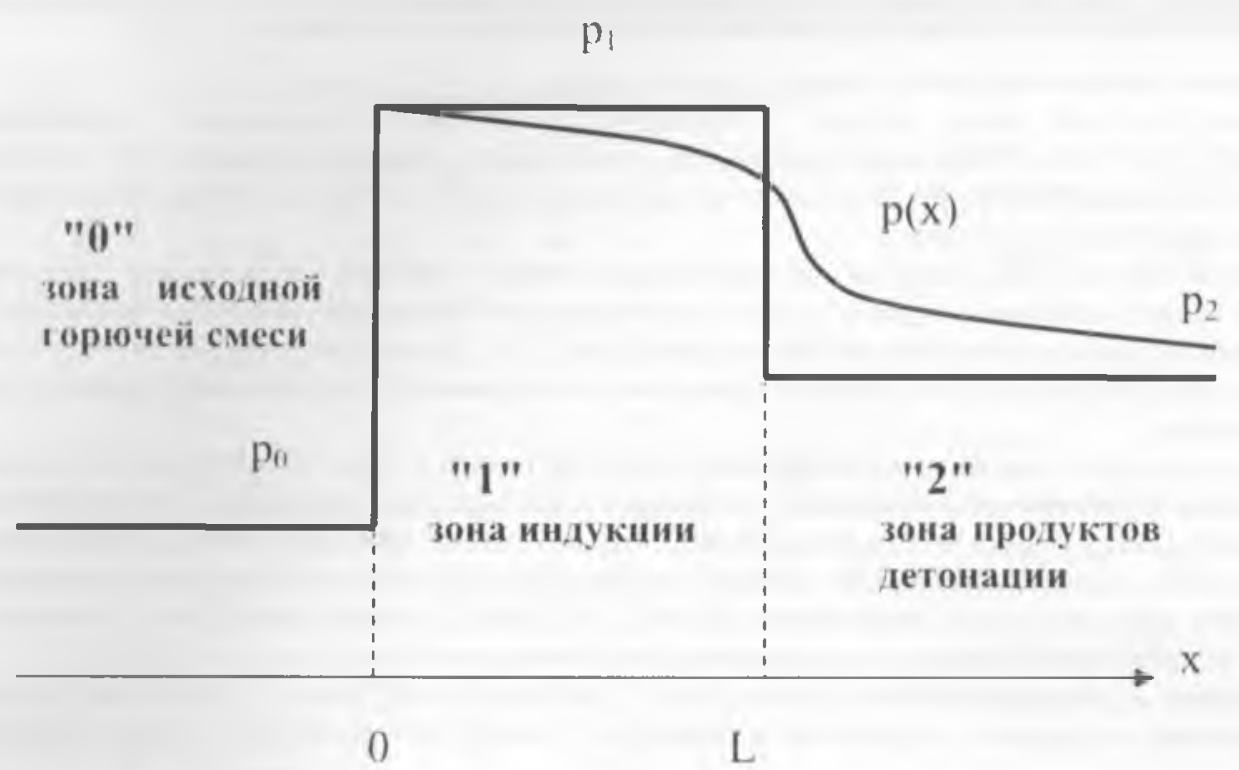

Рис. 2 - Профиль давления в ЗНД-модели детонационной волны и в двухфронтовой модели.

Естественным упрощением ЗНД-модели детонационной волны является так называемая двухфронтовая модель, которая предполагает наличие за ударным фронтом зоны индукции, где тепловыделение отсутствует, и зоны продуктов детонации, разделенных фронтом мгновенного сгорания $\mathrm{x}=0$ (см Рис.2). Эта модель вполне адекватно отражает детонационный процесс в гомогенных газовых смесях, а также во многих гетерогенных системах, так как в этих системах тепловыделению предшествует ряд сложных и весьма «медленных» физических процессов [2,6]. ГІравда, эта модель непригодна для описания детонации конденсированных взрывчатых веществ (КВВ), где интенсивное тепловыделение начинается непосредственно за ведуцим ударным фронтом [7,8] (см. Рис.3).

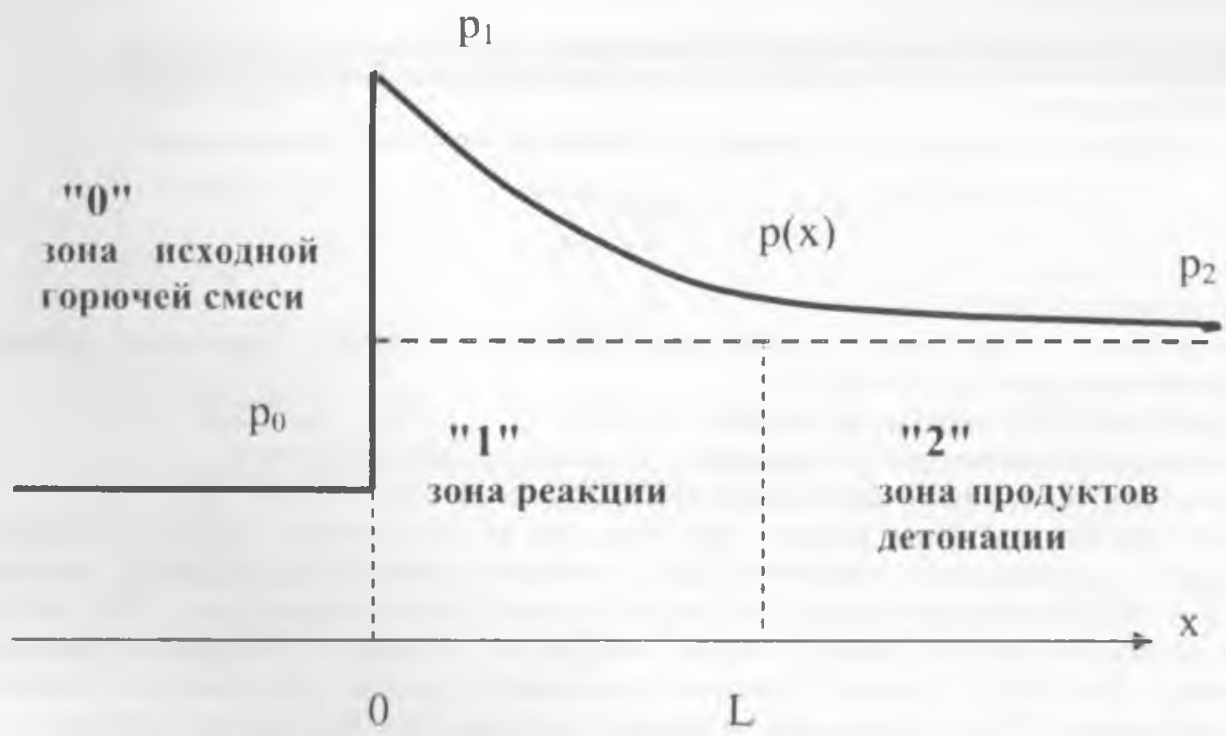

Рис. 3 - Профиль давления в ЗНД-модели детонационной волны в КВВ

С точки зрения взрывобезопасности наиболее важными представляются следующие проблемы теории детонации $[2,3,4]$ :

1) инициирование детонации;

2) структура детонационных волн; 
3) пределы детонации (концентрационные и по начальному давлению) и предельные детонационные режимы (спин, галоп);

4) выход детонации из канала или трубы в открытое пространство.

Все зти проблемы так или иначе связаны с проблемой устойчивости одномерной стацнонарной детонационной волны $[1,2,7-10]$. Исследование устойчивости стационарной детонации в модели ЧЖ сводится к вопросу об устойчивости ударной волны [5]. В этом случае модель как раз и не дает возможности однозначно ответить на вопрос об устойчивости детонации.

Исследование устойчивости стационарной детонационной волны в модели ЗНД весьма затруднено математически [11] и может быть пронзведено только приближенными методами. Наиболее продуктивные исследования устойчивости детонационной волны были ироизведены С.К. Аслановым в рамках двухфронтовой модели [12], главным недостатком которой является нарушение непрерывности распределения параметров за ведущим ударным фронтом.

Чтобы оценить возможность корректного применения двухфронтовой модели детонационной волны, а также для исследования устойчивости одномерной детонации в ЗНД-модели, необходимо предварительно решить задачу о распределении термо- и газодинамических параметров за ведушим ударно-детонационном фронтом. В первую очередь, интерес представляет профиль распределения давления, который можно построить либо путем численного интегрирования совместной системы уравнений газовой динамики и химической кинетики, либо путем аппроксимации данных эксперимента, если таковые имеются.

Распределение термо- и газодинамических параметров в детонационной волне за ведущим ударным фронтом рассчитано нами из законов сохранения и уравнения химической кинетики, которые образуют следуюшую систему

$$
\left\{\begin{array}{l}
\rho_{0} u_{0}=\rho_{1} u_{1}=\rho(x) u(x) \\
p_{0}+\rho_{0} u_{0}{ }^{2}=p_{1}+\rho_{1} u_{1}^{2}=p(x)+\rho(x) u^{2}(x) \\
\rho_{0} E_{0}+Q+p_{0}+\frac{\rho_{0} u_{0}{ }^{2}}{2}=\rho_{1} E_{1}+Q+p_{1}+\frac{\rho_{1} u_{1}^{2}}{2}=\rho(x) E(x)+\beta(x) Q+p(x)+\frac{\rho(x) u^{2}(x)}{2} \\
u(x) \frac{d \beta}{d x}=f(\beta(x), p(x), \rho(x)),
\end{array}\right.
$$

где $и$ - скорость потока,

$\rho$ - плотность,

$p$ - давление,

$E$ - удельная внутренняя энергия,

$Q$ - удельное тепловыделение в результате химической реакции,

$x$ - пространственная координата.

В частном случае совершенного (политропного) газа

$$
E=\frac{1}{\gamma-1} \frac{p}{\rho}+\text { const }
$$

где $\gamma$ - отношение теплоёмкостей.

Для расчетов разработан специальный программный комплекс в среде визуального объектноориентированного программирования $\mathrm{C}++$ Builder 6.0 .

ІІриложение содержит два пункта меню и три вкладки.

Пункт меню «Справка» предоставляет доступ к краткому руководству для пользователя

Пункт меню «Выход» дает возможность завершить работу приложения.

На первой вкладке приложения «База данных ВВ» (см. Рис.4) расположена таблица, содержаццая необходимую информацию о взрывчатых веществах (ВВ): название, химическую формулу, начальные давление, плотность и отношение теплоемкостей, а также средний молекулярный вес. Под таблицей расположены кнопки навигации по базе данных. Кнопки «Вставить», «Удалить», «Записать», выполняют функции редактирования самой базы данных. Кнопка «Копировать данные для расчета» выполняет копирование данных выбранного ВВ для проведения численного эксперимента. База данных сформирована в среде разработки MS Access 2003. 


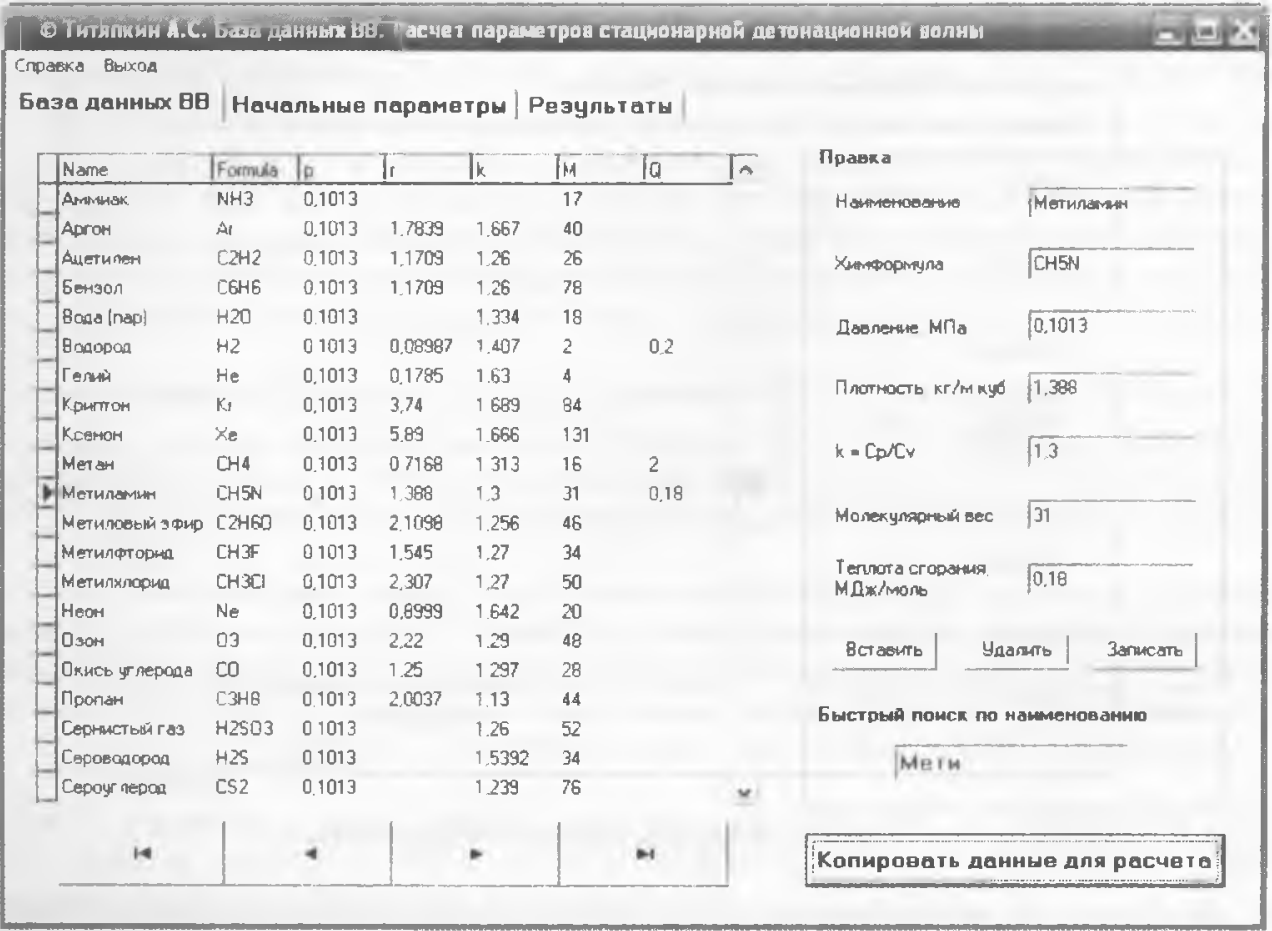

Рис. 4 - Вкладка проекта «База данных ВВ»

Вторая вкладка «Начальные параметры» (см. Рис.5) содержит данные о ВВ, окислителе, химической кинетике. Данные окислителя (кислород либо воздух) выбираются из выпадающего списка, после чего рассчитываются начальные параметры смеси. Далее необходимо выбрать уравнение химической кинетики и нажатием кнопки «Расчет» произвести расчет параметров в зоне индукции и за фронтом волны детонации. Имеется возможность контролировать изменение параметров в ходе расчета. Эти данные сохраняются в файле «Rezults.txt» в той же папке, где находится само приложение. После завершения расчета значения расчетных параметры отображаются на вкладке «Результаты» (см. Рис.6) Также строится график давления как функции расстояния до ведущего ударного фронта.

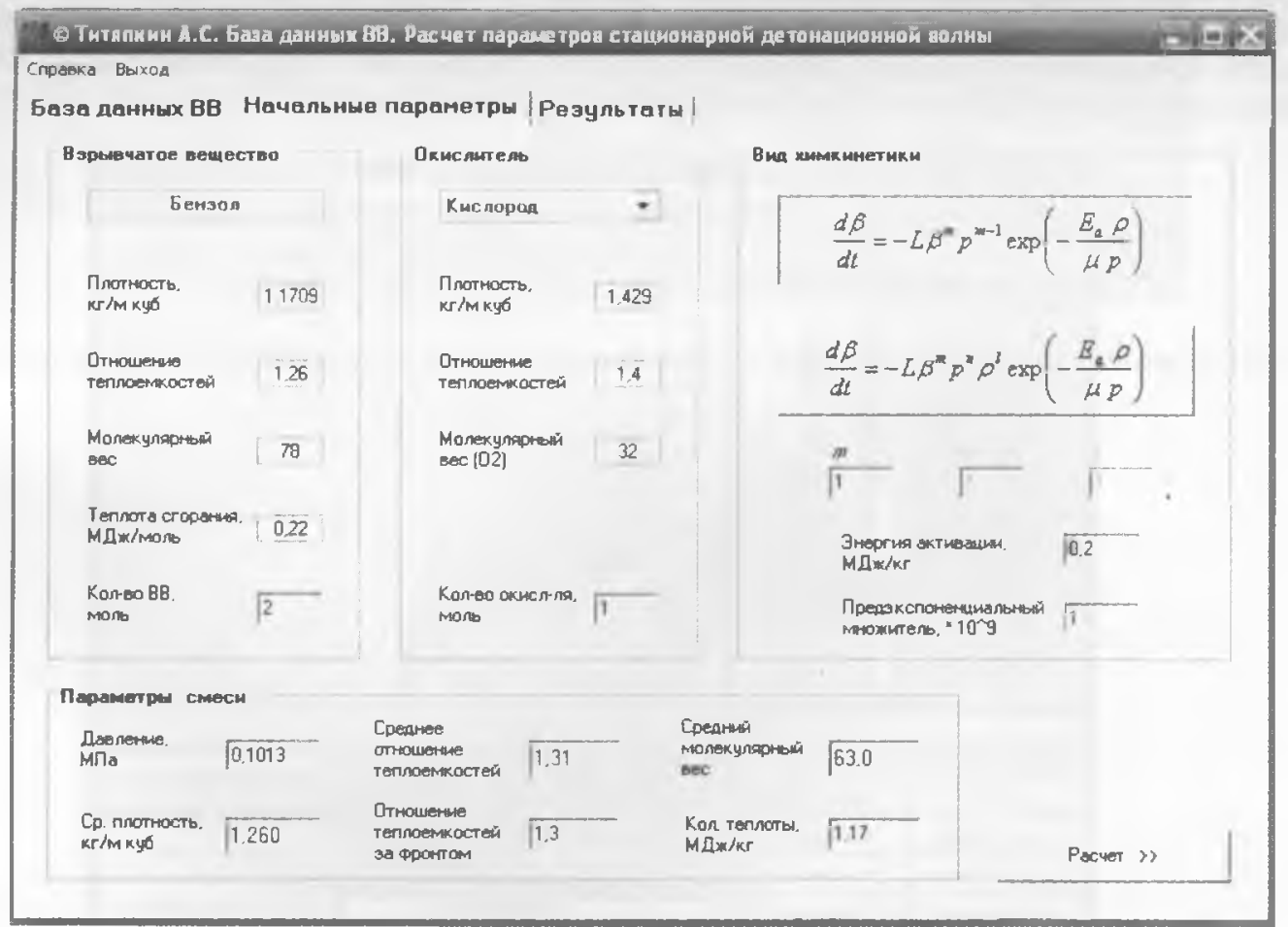

Рис. 5 - Вкладка проекта «Начальные параметры» 


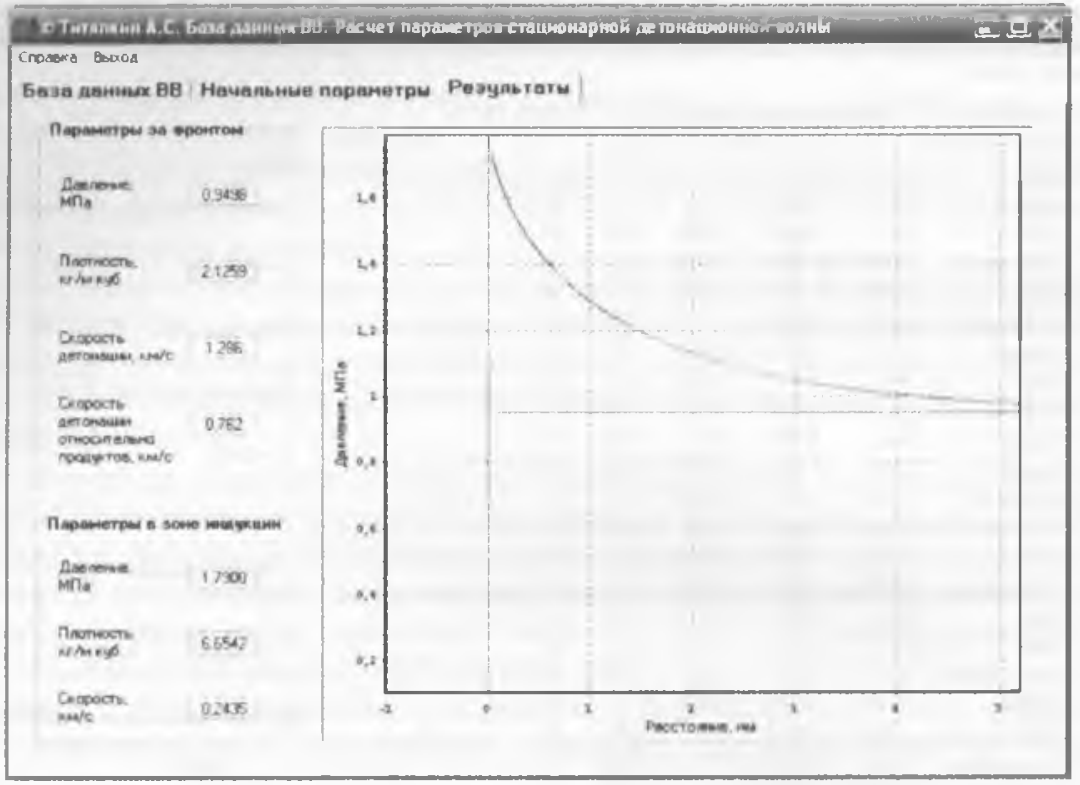

Рис. 6 - Вкладка проекта «Результаты»

Расчеты для газовых систем произведены на базе аррениусовской кинетики в разных её модификациях (при различных энергиях активации, с учетом обратной реакции и без неё и т.п.), применялись уравнения состояния как идеального (совершенного), так и реальных газов. Для детонации жидких ВВ при расчетах были использованы кинетические уравнения [7], а для твердых ВВ (тротил и т.п.) - кинетики [8,13]. Результаты контрольных расчетов совпали с результатами [7,14]. Обнаружено также хорошее соответствие с многочисленными экспериментальными данными

Для обработки полученных опытным путем зависимостей давления от расстояния до ведущего ударнодетонационного фронта разработана программа, позволяющая автоматически подбирать уравнение регрессии, наилучшим образом описывающее заданное распределение точек с применением способа наименыших квадратов [15]. Данная программа является универсальной в смысле вида обрабатываемых экспериментальных данных.

Интерфейсная часть программы, представленная на рис. 7, разработана также в системе визуального объектно-ориентированного программирования Borland C++ Builder 6.0. В среде разработки научнотехнических приложений Compaq Visual Fortran разработана математическая dl1-библиотека подпрограмм, предназначенных для построения регрессионных зависимостей.

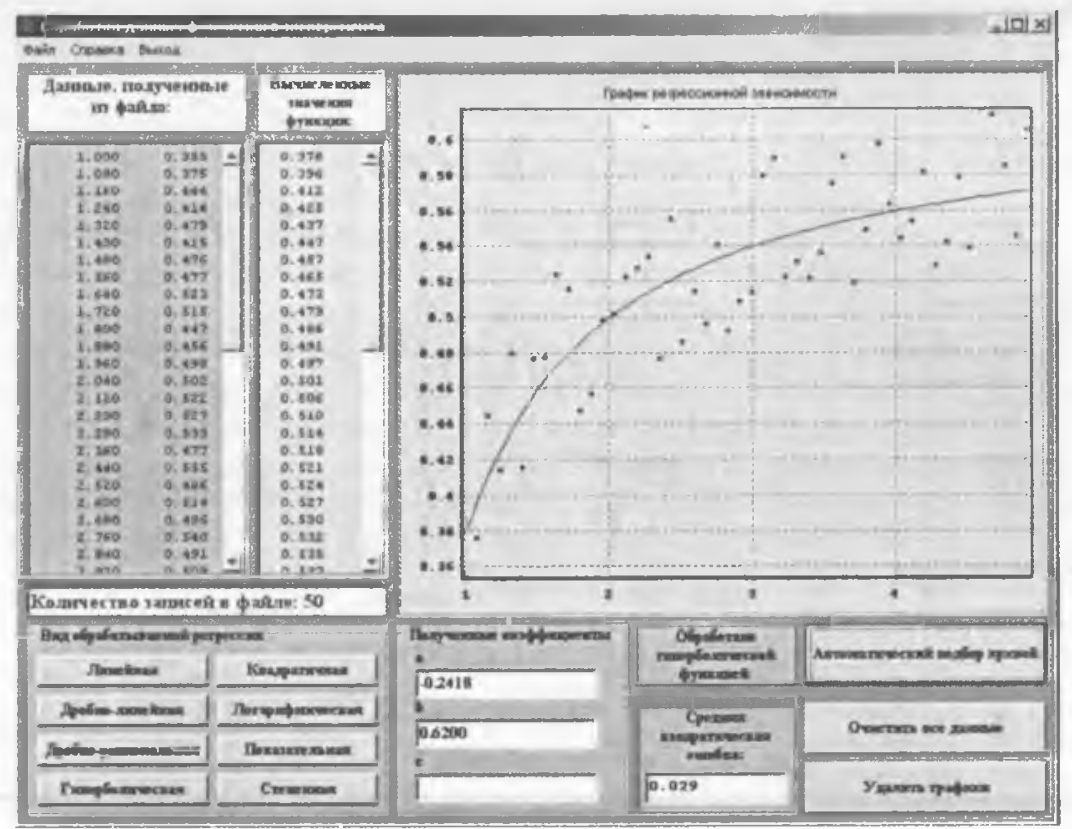

Рис. 7 - Интерфейс программы обрработки данных физического эксперимента 
Обнаружена следующая интересная особенность: профиль давления $p(x)$ или же безразмерная функция $P=p / p_{1}$ от безразмерной величины $\xi=x / L$ для стационарной детонации газовых систем имеет точку перегиба (см. Рис.2). Как пюказывают наши предыдушие исследования (см., например, [11]), хотя строго доказать этот факт очень сложно, все подобные детонационные комплексы неустойчивы по отношению к малым возмушениям. Это естественно, так как из (1) следует, что перегиб профиля давления означает также и перег иб профиля скорости за ударно-детонационным фронтом, а подобные течения имеют сильную тенденцию к неустойчивости, о чем свидетельствует, например, теория пограничного слоя [5]. Кроме того, ЗНД-модель в данном случае хорошо аппроксимируется двухфронтовым стационарным детонационным компјексом, который чеустойчив $[1,12]$.

В то же время, профиль давления $p(r)$ для стационарной детонации твердых ВВ точку перегиба не содержит, а подобные системы по нашим расчетам устойчивы (по крайней мере по отношению к крупно- и среднемасщтабным возмущениям - коротковолновые возмущения гасятся вязкостью), что подтверждается экспериментально. Для детонации жидких ВВ и гетерогенных систем столь однозначных выводов сделать нельзя.

ІІоказана также относительная узость зоны химической реакции при детонации конденсированных взрывчатых вешеств (КВВ) по сравнению с таковой в газовой детонации: при детонации конденсированных систем отсутствует «зона индукции» и энергичные химические превращения начинаются непосредственно за ведушим ударным фронтом. В газофазных гетерогенных системах область химических превращений относительно «растянута». ІІолученные расчетным путем результаты вполне согласуются с данными экспериментов по детонации.

Если принять сделанную выше хорошо обоснованную гипотезу о зависимости устойчивости детонационной волны от наличия точки перегиба в профиле давления в стационарном детонационном комплексе, решение проблемы устойчивости весьма упрощается.

Детальный анализ развития неустойчивости детонационной волны позволяет рассчитать структуру многофронтовой (ячеистой) детонации (см. Рис. 8,9), оценивая размер ячейки длиной волны возмущения с максимальной скоростью роста амплитуды [11]

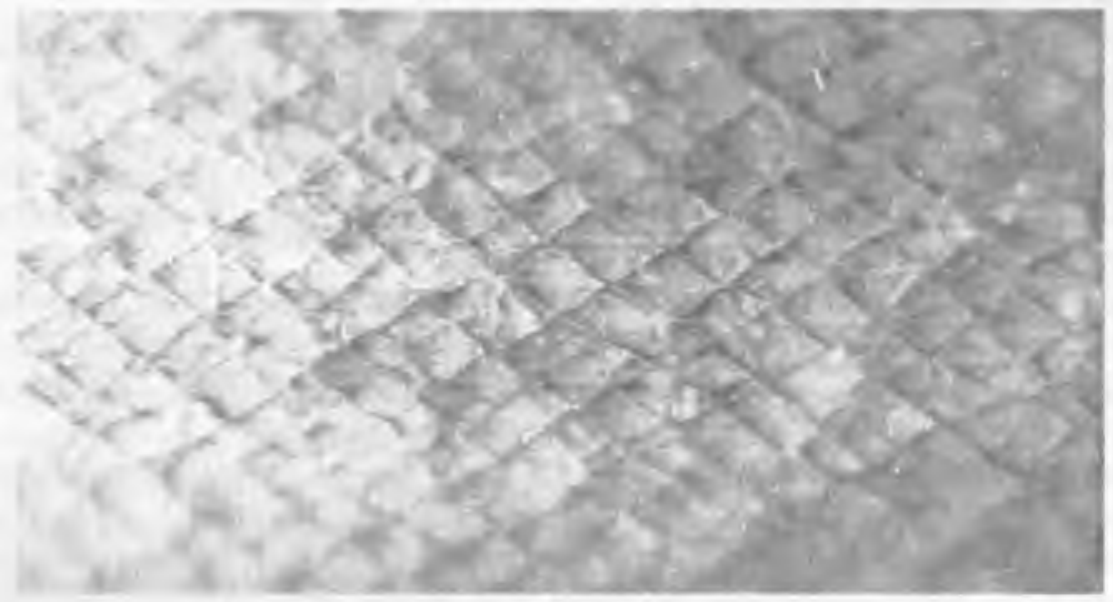

Рис. 8 - Ячеистая структура детонационной волны, зафиксированная следовым методом

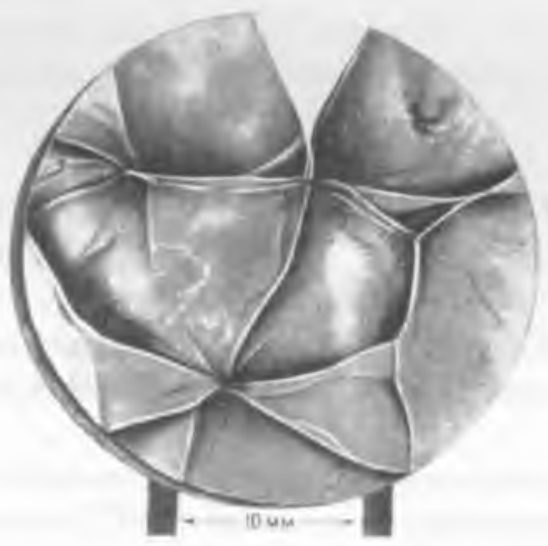

Рис. 9 - Ячеистая структура детонационной волны (вид с торца трубы) 
Можно также производить расчет параметров предельных детонационных режимов, таких как спин (см Рис. 10) и «галоп».

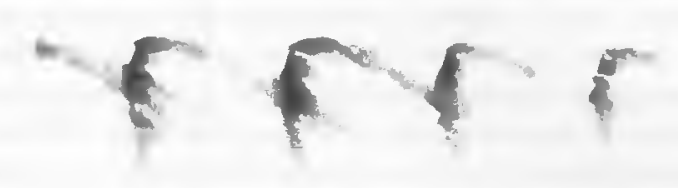

Рис. 10 - Фотог рафия головы детонационног спииа

Обратно пропорциональная зависимость размера детонационной ячейки от давления исходной горючей смеси позволяет управлять детонационным процессом, что немаловажно для решения практических проблем взрывобезогиасности $[2,4,11]$.

Онисанные выше программные комплексы является составной частью интеллектуальной системы поддержки принятия решений (ИСІІІ IP) по вопросам детонации конденсированных и газовых систем.

\section{Литература}

1. Щелкин К.И., Трошин Я К Іазодинамика горения. - М.: Изд-во АН СССР. - 1963. - 256с

2. Зверев И.Н., Смирнов Н.Н. Газодинамика горения. - М.: Изд-во МГУ. - 1987 - 307с.

3. Взрывные явления. Оценка и последствия: В 2-х кн. Кн.1 / Бейкер У., Кокс ІІ., Уэстайн П. и др. - М: Мир, 1986. $-319 \mathrm{c}$.

4. Нетлетон М. Детонация в газах. - М.: Мир - 1989. - 280с.

5. Јандау Л.Д., Лифшиц Е.М. Теоретическая физика. В 10 т. : Т. VI Гидродинамика. - М.: Наука. Гл. ред. физ.-мат. лит.- 1986. - $736 \mathrm{c.}$

6. Нигматулин Р.И. Динамика многофазных сред. Ч.1. - М: Гл. ред. Физ.-мат, лит. $1987 .-464 \mathrm{c}$.

7. Мейдер Ч Численное моделирование детонации. - М:Мир.- 1985.-384c.

8. Црёмин А.Н., Савров С.Д., Трофимов В.С., ІІведов К.К Цетонационные волны в конденсированных средах. - М.: Наука - 1970. -163с.

9. Коробейников В.П. Задачи теории точечного взрыва. - М.: Наука. Гл. ред. физ.-мат. лит., $1985 .-400$ с

10. Волков В.Э. Пределы детонации и проблемы взрывобезопасности. - Гаукові праці Одеської національної академії харчових технологій. - Одеса, 2006. - Вип. 28 - С. 194-199.

11. Асланов С.К., Волков В.Э., Царенко А.П. Математический анализ структуры детонационных волн в различных средах. // Вестник ОГУ. -1999.-Т.4.Вып 4. Физ.-мат.науки.- С.134.

12. Асланов С.К. Критерий неустойчивости детонации Чепмена-Жуге в газе. // Доклады АН СССР. -1965. Т. 163. №3-С.667.

13. Канель Г.И., Дрёмин А.Н. Разложение литого тротила в ударных волнах. // Физика горения и взрыва.-1977. Т.13.- №1. С. 85 .

14 Оран Э., Борис Дж. Численное моделирование реагируюших потоков. - М:Мир.- 1990-660с.

15. Мазмишвили А.И. Способ наименьших квадратов. - М.: Недра, 1968. - 440 с.

\section{РЕАЛИЗАЦИЯ ЗАДАЧИ ОЦЕНИВАНИЯ ПОКАЗАТЕЛЕЙ РАБОТЫ ЗАВОДА В АСУТП САХАРНОГО ПРОИЗВОДСТВА}

\section{Жуковский Э.И., докт. техн. наук, Скаковский Ю.М., канд. техн. наук, Витвицкий В.Д., Бабков А.В. Одесская национальная академия пищевых технологий}

Рассиатриваются вопросы реализации подсистеиы оперативиого учета основиых показателей работы сахарного завода. Подсистена функиионирует в составе АСУТП свеклосахарного производства.

The questions of realization of operative account subsystem basic indexes of sugar plant work are examined. A subsystent operates in computer system structure of sugar-beet production. 